\section{Capturing Consumer Preferences and Interests in Developing a State Plant Promotional Program}

\author{
Rebecca H. Wehry ${ }^{1}$, Kathleen M. Kelley ${ }^{2,4}$, Robert D. Berghage ${ }^{3}$, and
} James C. Sellmer ${ }^{3}$

Department of Horticulture, Pennsylvania State University, 301 Tyson Building, University Park, PA 16802

Additional index words. conjoint analysis, cluster analysis, gardening, landscaping, marketing, Spearman's rho, survey

Abstract. Two separate studies using intercept survey methodology were conducted to define the components of a state plant promotional program-Pennsylvania Gardener Selects (PGS) - based on consumer preference and appeal. The first study, conducted 6 and 7 Mar. 2003 at the Philadelphia Flower Show in Philadelphia, Pa., involved 243 Pennsylvanians. Objectives were to define current gardening-related shopping habits, sources of gardening information, motives and limitations for pursuing gardening, and history of purchasing other Pennsylvania products. Responses were analyzed using cluster analysis to identify consumer-gardener segments that would potentially purchase PGS plants. Three distinct consumer segments were generated: "Novice Gardeners" (consumers with limited experience in gardening), "Casual Gardeners" (consumers with limited confidence in their gardening knowledge), and "Avid Gardeners" (consumers who express great interest in gardening). "Avid Gardeners" exhibited a greater level of interest in purchasing plants evaluated for Pennsylvania (average response, 6.5 ; based on a scale of 1 to 7 , where 1 is very unlikely and 7 is very likely), with $73 \%$ indicating that they had purchased Pennsylvania products; hence, they were a potential market for PGS plants. The second study, conducted 8 to 10 Mar. 2004 at the Philadelphia Flower Show involved 250 Pennsylvanians. Objectives for this study were to define consumer brand and product preferences, including container colors for the PGS program, plant tag style/color, and retail price (based on a scale of 1 to 7 , where 1 is very unlikely to purchase and 7 is very likely to purchase), as well as brand attributes these consumers valued. Responses were analyzed using conjoint analysis. Participants awarded the highest utilities to the white container with a black-and-white PGS logo (0.1149), keystoneshaped tag with color image and PGS logo $(0.1099)$, and a retail price of $\$ 1.98(0.4751)$. Spearman's rho was used to identify relationships among existing and related brand attributes. Correlations between participants' response to brand attributes, including locally grown, ideal for local conditions, quality assurance, and independent testing program, as well as plant guarantee and publication with gardening tips, suggest that promotional materials should emphasize and include these qualities. Results from these studies indicate that there is interest in a state plant promotional program for Pennsylvania. To use resources wisely, consumers classified as "Avid Gardeners" would be the most appropriate to target first. To attract consumer attention and encourage purchasing at a retail outlet, containers and plant tags should have distinctive colors, and brand attributes and resulting consumer benefits should be emphasized on promotional materials.

Promotional programs and associated brands have been introduced by many state grower and gardener associations and commercial plant growers throughout the country. These programs have experienced

\footnotetext{
Received for publication 19 Sept. 2006. Accepted for publication 10 Jan. 2007.

Funded by the Pennsylvania Landscape and Nursery Association.

Use of trade names does not imply endorsement of the products named or criticism of similar ones not named.

${ }^{1}$ Graduate student.

${ }^{2}$ Assistant professor.

${ }^{3}$ Associate professor.

${ }^{4}$ To whom reprint requests should be addressed; e-mailkmk17@psu.edu
}

variable success rates with growers, retailers, and consumers. Successful programs, like the highly regarded Texas Superstar, have a dynamic marketing strategy. As a result of Texas Superstar marketing efforts, 90,374 Tagetes erecta L. 'Antigua' were sold in 1990 , and 96,460 plants were sold in 1991 compared with 1000 plants sold in 1989, the year before any Texas Superstar promotional efforts (Mackay et al., 2001). In 1999, Penn State Master Gardeners and commercial growers created a state evaluation and promotional program, called Pennsylvania Gardener Selects (PGS) (Sellmer et al., 2003). Pennsylvania Gardener Selects attributes or brand characteristics include 1) plants that are grown in Pennsylvania, 2) plants that are ideal for environmental conditions throughout the state, 3) quality assurance as a result of 44 trial locations, and 4) an independent testing program (Sellmer et al., 2003).

Today, consumers rarely make a purchase because of the need for a specific branded product; rather, they will buy the brand because it fulfills a fundamental desire (Iacobucci, 2001). Consumers expect the brand's promoters to have a solid understanding of their needs and culture (Gobe, 2001). The starting point for a successful marketing strategy is appreciation of the targeted consumer's wants and desires, and the underlying reason the consumer values these desires (Crawford and Mathews, 2001). A brand like PGS could target "Novice Gardeners", consumers who are unsure which plants are appropriate for their personal garden, and inform them that PGS plants are appropriate for their landscape garden and would produce outstanding results based on selection criteria. In addition, the plant material could appeal to the experienced gardener as a result of quality assurance (Doeckel, 2002).

In concept, PGS and most other state plant promotional programs are designed to help growers, retailers, and consumers to identify outstanding plants for their local environment. For these programs to be successful, a promotional effort is needed to inform potential consumers about the plant's value and benefits of using them in the landscape. With the increase in the number of green industry branding efforts, interest in understanding the effectiveness of visual content such as point of purchase (POP; e.g., graphic design, signs and accessories) and packaging materials (e.g., container color/style) has grown. Packaging communicates $60 \%$ of brand attributes (Doeckel, 2002), and presentation, a component of POP, is the second most important factor that influences consumer purchasing, preceded only by product quality (Naab, 2003). Presentation involves the visual appearance and packaging, and conveys the brand's persona and character (Gobe, 2001). One study demonstrated the importance of presentation with regard to branding in a retail situation. Researchers placed white, lipstick, pink, and red impatiens (Impatiens walleriana Hook. F.) cultivars, labeled with a fictitious brand name, on benches surrounded by coordinating tags, signs, and other POP material (Creel, 2004). Unbranded impatiens, which served as a control, were also placed in the same garden centers and marketed without any POP material. Regardless of a $25 \%$ higher retail price, branded plant material outsold nonbranded plant material by $40 \%$.

When designing the brand's visual appearance, there are some key components that should appear on POP material. Plant tags should contain the retail price, picture of the plant, name of plant (common name, genus, and species), brand name, and cultural information such as flower or foliage performance, growth habit, hardiness zone, sun/ shade, and soil requirements (Gibson and Greer, 2003). Plant containers should display the brand name, brand logo, and store name. Bench cards should be placed directly above or beside the product. 
To develop a brand's persona or characteristics further, national brands rely on brand attributes to communicate their message to potential consumers. Proven Winners offers a website with gardening tips, publishes a gardening newsletter, and sponsors a gardening TV program (Henne, 2002a). Simply Beautiful, as well as other national brands, offers POP materials to retailers, provides a consumer-oriented website with gardening information, and has a perceived level of quality associated with the brand name (Henne, 2002b). Pennsylvania Pride Nursery Products provides a 3-year plant guarantee as one of its brand attributes (Eaton Farms, 2003).

Visual presentation may also provide a service for consumers by helping them identify specific brands within a retail environment and may provide retailers with a way to differentiate their product offering and ultimately obtain higher profits (Naab, 2003).

Two separate consumer-oriented surveys were conducted with the intent of using the data to develop further the PGS state plant promotion - specifically, what gardening segments should be targeted and what POP materials and brand attributes should be incorporated into the final product design. Additionally, data could assist representatives from other state plant promotional programs with either developing a similar program or enhancing an already established program. The main objective of the first study was to determine which gardening segments would be the primary target for a marketing strategy developed for the PGS program based on current gardening-related shopping habits, sources of gardening information they use, motives and limitations for pursuing gardening, and history of purchasing other Pennsylvania products. Objectives for the second study were to define consumer brand and product preferences, including container colors for the PGS program, plant tag style/color, and retail price, as well as brand attributes these consumers valued. Participants also answered demographic questions including household income, age, education, state of residence, and household size. The Office of Research Protection at the Pennsylvania State University approved both surveys and resulting interactions with human participants.

\section{Materials and Methods}

Study 1: Identifying potential Pennsylvania Gardener Selects purchasers. An intercept survey was conducted at the 2003 Philadelphia Flower Show, 6 and 7 Mar. 2003, in Philadelphia, Pa. The Philadelphia Flower Show is an annual event that attracts gardening enthusiasts from the mid-Atlantic states to view the newest trends in garden and floral design. The survey was administered adjacent to the Penn State Cooperative Extension "Ask the Expert" booth, where attendees could ask extension personnel gardening, landscape, and plant-related questions.

Survey responses were separated based on state of residence, and only Pennsylvania participant responses were analyzed. This segmentation was done to isolate the primary target audience of the PGS program: Pennsylvania citizens. Cluster analysis (version 11.0; SPSS, Chicago) was performed to determine whether meaningful consumer segments could be identified. Cluster analysis is used by marketers to find similarities between survey participants based on responses to select survey questions, and then "enables these subjects to be placed in clusters" (Kress, 1988, p. 288). Resulting clusters are then used for market segmentation. Cluster analysis has been used by researchers to define consumer segments related to their preference for horticultural products, such as edamame (edible Glycine $\max$ [L.] Merrill) (Kelley and Sanchez, 2005), and professional landscapers' and nursery operators' general perceptions and implementation of Integrated Pest Management (IPM) principles and practices (Sellmer et al., 2004a, b).

Variables used to create consumer gardening clusters were 1) consumers' willingness to purchase plant material evaluated and chosen for Pennsylvania, 2) whether they felt qualified to make purchasing decisions about landscape plant material, 3) whether they are sought after for gardening advice, and 4) whether they have purchased Pennsylvania products in the past. These questions established the participant's comfort level with gardening, familiarity and use of Pennsylvania products, and their potential level of interest in a program like PGS. Using K-Means, the three-cluster solution with seven-cluster algorithms was chosen. Resulting groups were then analyzed to determine whether significant differences existed between them with using the Mann-Whitney test $(P \leq 0.05)$ and two-tailed $t$ test $(P \leq$ 0.05 ; version 11.0, SPSS).

Study 2: Preference for Pennsylvania Gardener Selects point-of-purchase material, retail price, and brand attributes. A second intercept survey was conducted at the Philadelphia Flower Show 8 to 10 Mar. 2004. Participants were self-selected, viewed photographic images of Verbena $\times$ hybrida Voss 'Tapien Salmon', and were asked to rate each image based on the importance of three factors on their decision to purchase the plant for use in their garden: 1) container color, 2) plant tag style/color, and 3) retail price. Verbena, selected as a PGS plant in 2001, was chosen for this study because of its compact form, which allowed the researchers to photograph the plant with the POP material and develop a large enough image to show the detail of the subject.

There were varying levels of complexity within each of these factors. Container color consisted of 1) a standard $530-\mathrm{cm}^{3}$ black plastic container, 2) a white $530-\mathrm{cm}^{3}$ container with a black-and-gray PGS logo, or 3) a $530-\mathrm{cm}^{3}$ blue container with a color PGS logo. White containers were included in this study because they are used by many national brands, including Proven Winners (Sycamore, Ill.) and Simply Beautiful (West Chicago, Ill.). Blue containers were included in the study based on results from a focus group session conducted in 2002 to determine consumer preference for proposed PGS logos and plant tag options (Whery, 2004). Plant tags styles/ colors consisted of 1) a white "slim" tag with the PGS brand name and plant genus, species, and cultivar name printed in black ink (Table 1);2) a white "slim" tag with a blackand-gray PGS logo, a color image of verbena in peak flower, and the genus, species, and cultivar name printed in black ink; or 3) a larger tag with a color image of verbena in peak flower, and the genus, species, and cultivar names, which were printed on top of the image along with a color PGS logo. The decision to use color images of verbena, PGS logos, and the concept of the keystone symbol on the tags was also based on recommendations from a focus group session conducted in 2002 (Whery, 2004). The final level consisted of a tag in the shape of a keystone (Pennsylvania state symbol) with a large color image of verbena, symbols representing plant cultural conditions, or a color PGS logo (Table 1).

The third factor consisted of three retail price points: $\$ 1.98$ (chosen based on average retail prices observed at select garden centers that stocked PGS plant material during the spring of 2003), $\$ 2.49$, or $\$ 3.29$. A retail price of $\$ 2.49$ was chosen because it represented the average price for annuals in $530-\mathrm{cm}^{3}$ pots in the mid-Atlantic region in 2003 (Miller, 2003). The final price point of $\$ 3.29$ was chosen to explore the upper limits of what consumers would pay for a branded annual plant.

A total of 36 combinations (three container colors $\times$ four plant tag styles/colors $\times$ three retail prices) were possible. Using an orthogonal design generated by OrthoPlan, a computer software program component of SPSS software (version 11.0; SPSS), 16 combinations were produced to reduce participant fatigue that would have resulted from evaluating all 36 combinations. OrthoPlan generated this design by randomizing the specific combinations of factor levels while maintaining the required balance. Thus participants viewed all image combinations at an equal rate, without becoming overwhelmed by the total possible number of combinations. Results were analyzed using conjoint analysis to estimate consumer tradeoffs when making purchasing decisions between products (Talaga and Tucci, 2001). Conjoint analysis is recognized as being a valuable market research tool in product design (SPSS conjoint 8.0; SPSS), and has been used by researchers to determine which product features consumers feel are important when selecting horticultural goods that will meet a need or want (Kelley et al., 2001, 2002). By using conjoint analysis, several product features (e.g., price, color, size) can be compared with each other at the same time. This strategy is similar to how consumers appear to make decisions in the marketplace when choosing a product, from several available, each with multiple features and various levels of options within each feature (SPSS conjoint 8.0; SPSS). 
Participants were asked to rate each combination of verbena, POP materials, and retail prices on a 7 -point Likert scale $(1=$ very unlikely, $7=$ very likely) (Bruner and Hensel, 1996), with regard to how likely they would be to purchase the combinations at a retail outlet for use in their garden. Two $10.2-\mathrm{cm}$ long by $10.2-\mathrm{cm}$ wide images were placed side by side on a $27.5-\mathrm{cm}$ long by $21.25-\mathrm{cm}$ wide piece of paper, resulting in eight sets of images assembled in a flip book. The Likert scale was then placed directly under each image. When both images on a page were rated, participants turned the page to reveal a new set of images and scales.

After viewing and rating each of the 16 images separately, participants answered additional survey questions, including those related to 1) which brand attributes they valued, 2) their gardening experiences and preferences, and 3) demographics. Responses were separated based on state of residence, and only responses from Pennsylvania residents were used for analysis. This segmentation was done to isolate the primary target audience of the PGS program: Pennsylvania citizens. Correlations between brand attributes were analyzed using Spearman's rho $(\alpha=0.05$; version 11.0, SPSS).

\section{Results}

\section{Study 1: Identifying potential Pennsylvania Gardener Selects purchasers}

General demographics and statistics. Of the 441 individuals who participated in the intercept survey, 243 were from Pennsylvania and were included in further analysis. Eighty-eight percent of the Pennsylvania participants were female. Forty-two percent were age 51 years or older, $53 \%$ had an education level of a high school diploma or less, and $70 \%$ had a household income greater than or equal to $\$ 50,000$ annually. Seventy percent had purchased Pennsylvania products in the past.

Ninety-two percent had an area in their yard that they used as a garden. Respondents had been gardening for an average of 19 years and shopped for landscape plant material an average of 1.8 times a month throughout the gardening months of May to Aug. Participants spent an average of $1.8 \mathrm{~h}$ in the retail garden center during each of these visits.

Three distinct segments were identified through cluster analysis: "Avid Gardeners" (50\% of participants), "Novice Gardeners" (38\%), and "Casual Gardeners" (27\%; Table $2)$. Two separate statistical analyses were conducted: 1) a comparison between survey responses for "Avid Gardeners" (more involved and interested gardeners who are a primary target audience of the PGS marketing effort) and responses for all other Pennsylvania survey participants, and 2) a comparison of survey responses for "Novice Gardeners" and "Casual Gardeners". Neither the "Novice Gardeners" nor the "Casual Gardeners" appear to be a primary target market for the PGS program, but strategies could be implemented, such as promoting the program and educating potential consumer segments about the benefits of purchasing PGS plants, which might appeal to either group and encourage them to seek out PGS plants actively. Overall, "Novice Gardeners" exhibit characteristics of a beginning gardener: "Neutral" describes their response to the question regarding their abilities, and this group relies on others for input when deciding where to make landscape plant purchases. "Casual Gardeners" appear to be less interested in the focus of the PGS program and are less confident in their plant selection abilities, but the availability of a diverse plant selection or unusual species may inspire them and prompt an interest in seeking such products.

"Avid Gardeners" versus other participants. The largest segment, with 117 participants (50\% of the respondents), was "Avid Gardeners". On a scale of 1 to 7 (where 1 is very strongly disagree and 7 is very strongly agree), these gardeners felt the most confident when making decisions about landscape plants they purchased for their garden (average, 5.7; Table 2). The majority $(74 \%)$ of this segment was also sought after by neighbors, friends, and family for gardening advice. These gardeners were also most willing to purchase plant material evaluated and chosen for Pennsylvania (average, 6.5; where 1 is very unlikely and 7 is very likely).

"Avid Gardeners" were most likely to have an area in their yard that they used as a garden $(97 \%)$, and had been gardening for longer (average, 20.8 years; Table 2) than the other participants. "Avid Gardeners" were most likely to garden to keep the outside of their home beautiful $(90 \%)$, to relax $(75 \%)$, to experiment with new plant material $(40 \%)$, to increase their property value $(33 \%)$, and to teach children about gardening ( $29 \%$; Table 2$)$.

When asked where they purchased or how they obtained landscape plant material, "Avid Gardeners" were most likely to purchase or obtain landscape plant material from local nurseries/garden centers $(82 \%)$, friends or neighbors $(50 \%)$, and from catalog companies (34\%; Table 2). "Avid Gardeners" shopped for or purchased landscape plant material most often during the months of April (average, $2.3 \mathrm{~h} /$ month), May (average, $3.2 \mathrm{~h} / \mathrm{month}$ ), June (average, $2.8 \mathrm{~h} /$ month), July (average, $1.4 \mathrm{~h} /$ month), and August (average, $1.5 \mathrm{~h} /$ month; Table 2). They were most likely to shop for plant material at festivals or events at garden retailers $(43 \%)$, and they shopped at their store of choice based on plant quality $(62 \%)$ and diverse plant selection and unusual species (43\%; Table 2).

"Avid Gardeners" used a variety of resources to obtain information about gardening. They were most likely to gather gardening information from books (64\%), friends/family/neighbors (63\%), gardening programs on public and cable television (43\% and $32 \%$ respectively), garden radio programs $(27 \%)$, university websites $(17 \%)$, and garden center staff (14\%; Table 2$)$.

The only significant demographic separating the segments was the level of education. 
Table 2. Descriptions of three consumer segments derived from cluster analysis based on participant responses from an intercept survey conducted at the Philadelphia Flower Show in Philadelphia, Pa., 6 and 7 Mar. 2003, regarding their willingness to purchase plant material evaluated and chosen for Pennsylvania, if they felt qualified to make purchasing decisions about landscape plant material, if they are sought after for gardening advice, and if they have purchased Pennsylvania products in the past.

\begin{tabular}{|c|c|c|c|c|}
\hline Attribute & "Avid Gardener" & "Novice Gardener" & "Casual Gardener" & Significance \\
\hline No. of participants & 117 & 89 & 27 & NA \\
\hline Percentage of participants & 50 & 38 & 12 & NA \\
\hline \multicolumn{5}{|c|}{ Mean who feel qualified to make decisions about landscape plant material } \\
\hline$(1=$ strongly disagree, $7=$ strongly agree $)$ & 5.7 & 4.6 & 2.5 & $3 *$ \\
\hline Sought after for gardening advice $(\%)$ & 74 & 54 & 56 & $1 *$ \\
\hline \multicolumn{5}{|l|}{ Mean willingness to purchase plants evaluated for Pennsylvania } \\
\hline$(1=$ very unlikely, $7=$ very likely $)$ & 6.5 & 4.2 & 2.5 & $3 *$ \\
\hline Purchased Pennsylvania products in the past (\%) & 73 & 83 & 67 & NS \\
\hline Have an area in the yard for a garden $(\%)$ & 97 & 89 & 92 & $1 *$ \\
\hline Mean time gardening $(y)$ & 20.8 & 16.1 & 17.6 & $1 *$ \\
\hline \multicolumn{5}{|l|}{ Reasons for gardening $(\%)$ : } \\
\hline To relax & 75 & 60 & 67 & $1 *$ \\
\hline To keep the outside of the home looking beautiful & 90 & 82 & 82 & $1 *$ \\
\hline To teach child/children about gardening & 29 & 8 & 19 & $1 *$ \\
\hline To increase property value & 33 & 16 & 26 & $1 *$ \\
\hline Neighbors/community expect a garden to surround the home & 5 & 8 & 4 & NS \\
\hline To experiment with new plant material & 40 & 19 & 19 & $1 *$ \\
\hline \multicolumn{5}{|l|}{ How landscape plant material was purchased/obtained (\%): } \\
\hline Provided by landscaper & 20 & 14 & 22 & NS \\
\hline Purchased at local nursery/garden center & 82 & 66 & 74 & $1 *$ \\
\hline Purchased from catalog company & 34 & 17 & 30 & $1 *$ \\
\hline Purchased at home improvement store (Lowe's, Home Depot) & 11 & 8 & 7 & NS \\
\hline Purchased at discount store (Wal-Mart) & 44 & 51 & 56 & NS \\
\hline Purchased on the Internet & 61 & 45 & 59 & NS \\
\hline Obtained from neighbor/friend & 50 & 28 & 33 & $1 *$ \\
\hline Purchased at a roadside stand/farmer's market & 45 & 38 & 37 & NS \\
\hline Mean time spent in one visit at a garden retailer $(\mathrm{h})$ & 1.8 & 1.8 & 1.4 & NS \\
\hline \multicolumn{5}{|c|}{$\begin{array}{l}\text { Mean time spent shopping for or purchasing landscape plant material during the } \\
\text { following mo. (h): }\end{array}$} \\
\hline April & 2.3 & 1.2 & 1.2 & $1 *$ \\
\hline May & 3.2 & 2.6 & 2.4 & NS \\
\hline June & 2.8 & 1.7 & 1.9 & $1 *$ \\
\hline July & 1.4 & .6 & .6 & $1 *$ \\
\hline August & 1.5 & .5 & .8 & $1 *$ \\
\hline \multicolumn{5}{|l|}{ When participants shopped for plant material (\%): } \\
\hline While running errands & 21 & 30 & 22 & NS \\
\hline On the way home from work & 9 & 14 & 15 & NS \\
\hline At festivals/events at garden retailers & 43 & 24 & 37 & $1 *$ \\
\hline While visiting with friends & 11 & 15 & 7 & NS \\
\hline Just before planting them & 74 & 64 & 63 & NS \\
\hline \multicolumn{5}{|l|}{ Why shop at store of choice $(\%)$ : } \\
\hline Knowledgeable staff & 49 & 42 & 41 & NS \\
\hline Recommended by friends & 16 & 22 & 4 & $2 *$ \\
\hline Landscaper shops there & 3 & 5 & 7 & NS \\
\hline Diverse plant selection/unusual species & 43 & 19 & 37 & $3 *$ \\
\hline Plant quality & 62 & 46 & 48 & $1 *$ \\
\hline Convenient location & 44 & 40 & 33 & NS \\
\hline Florist on staff & 3 & 5 & 7 & NS \\
\hline Price & 34 & 33 & 26 & NS \\
\hline Attractive displays & 16 & 17 & 11 & NS \\
\hline Informative signage & 9 & 5 & 7 & NS \\
\hline \multicolumn{5}{|l|}{ Where gardening information was obtained $(\%)$ : } \\
\hline University websites & 17 & 6 & 4 & $1 *$ \\
\hline Horticultural company websites & 54 & 47 & 41 & NS \\
\hline Websites created by home gardeners & 18 & 14 & 4 & NS \\
\hline County extension office & 16 & 10 & 11 & NS \\
\hline Garden radio programs & 27 & 11 & 11 & $1 *$ \\
\hline Gardening programs aired on public TV stations & 43 & 24 & 37 & $1 *$ \\
\hline Gardening programs aired on cable networks & 32 & 21 & 19 & $1 *$ \\
\hline Garden center staff & 14 & 3 & 4 & $1 *$ \\
\hline Home improvement staff & 21 & 23 & 26 & NS \\
\hline Friend/neighbor/family member & 63 & 46 & 48 & $1 *$ \\
\hline Master gardener program & 6 & 5 & 0 & NS \\
\hline Books & 64 & 36 & 41 & $1 *$ \\
\hline Gardening magazines & 36 & 28 & 26 & NS \\
\hline Female participants $(\%)$ & 86 & 89 & 89 & NS \\
\hline Participants age 50 and younger (\%) & 59 & 57 & 54 & NS \\
\hline Bachelor's degree and greater $(\%)$ & 59 & 33 & 48 & $1 *$ \\
\hline Income $\geq \$ 50,001 / y(\%)$ & 70 & 71 & 72 & NS \\
\hline Single-adult households (\%) & 65 & 16 & 25 & NS \\
\hline No children in the household (\%) & 18 & 60 & 75 & NS \\
\hline
\end{tabular}

NS, ${ }^{*}$ Nonsignificant or significantly different at $P \leq 0.05$ (based on a two-tailed $t$ test and Mann-Whitney test). $1=$ cluster 1 tested against cluster 2 and 3 combined; $2=$ cluster 2 tested against cluster 3 ; and $3=$ comparisons for 1 and 2 are both significantly different. 
"Avid Gardeners" were most likely to have a bachelor's degree or higher (59\%) than other participants.

"Novice Gardeners" versus "Casual Gardeners". "Novice Gardeners" were the second largest segment of gardener-consumers identified, accounting for 89 participants (38\% of the respondents), whereas "Casual Gardeners", the smallest segment, accounted for 27 participants ( $12 \%$ of the respondents). "Novice Gardeners" were neutral in their confidence to make decisions about the landscape plant material they purchased (average, 4.6; where 1 is strongly disagree and 7 is strongly agree; Table 2) whereas "Casual Gardeners" felt less confident (average, 2.5). "Novice Gardeners" were neutral in their interest in purchasing plants evaluated and chosen for Pennsylvania (average, 4.2 ; where 1 is very unlikely and 7 is very likely) compared with "Casual Gardeners", who displayed little interest (average, 2.5).

Other differences between these two segments included why they shop for plant material at their store of choice. "Novice Gardeners" were most likely to shop at their store of choice because friends recommended the location $(22 \%)$, compared with "Casual Gardeners" (4\%). "Novice Gardeners" placed less value on diverse plant selection and unusual species (19\%) compared with "Casual Gardeners" (37\%).

\section{Study 2: Preference for Pennsylvania Gardener Selects point-of-purchase material, retail price, and brand attributes}

General demographics and gardening habits. Of the 420 individuals who participated in the intercept survey, 250 were from Pennsylvania and were used in the analysis. Eighty-three percent of the Pennsylvania participants were female. About half were 51 years of age or older $(53 \%)$, had at least a bachelor's degree (52\%), and had an annual household income greater than or equal to $\$ 80,000$ (50\%). Participants reported they had been gardening for an average of 20 years. Respondents participated in the following gardening activities: landscape gardening (flowers/trees/shrub gardening, 74\%), houseplant gardening $(62 \%)$, container gardening (54\%), vegetable/herb gardening (45\%), and water gardening (13\%). Respondents indicated their involvement in all gardening activities presented and, based on their responses, percentages sum to more than $100 \%$.

Conjoint analysis. Of the 250 Pennsylvanian participants, 233 complete survey responses were used for the conjoint portion of the analysis. Seventeen incomplete surveys were excluded from the analysis. Regression was performed, relating the product attributes to the product rating (version 11.0; SPSS). Pearson's $R$ statistic, with a value of 0.861 , was significant, with a $P$ value $=0.0001$ indicating a general agreement between the estimated utilities of the verbena images and the participant rankings (version 11.0, SPSS; Table 3).

The averaged importance for each of the three factors was container color (31.94\%),
Table 3. Conjoint analysis of participant ratings of container color, plant tag style/color, and retail price based on viewing images of Verbena $\times$ hybrid 'Tapien Salmon' at the 2004 Philadelphia Flower Show 8 to 10 Mar. 2004.

\begin{tabular}{lcr}
\hline & $\begin{array}{c}\text { Average } \\
\text { importance } \\
(\%)^{z}\end{array}$ & Utility $^{y}$ \\
Factor & 31.94 & \\
\hline Container Color & & -0.1408 \\
Black & & 0.1149 \\
White & & 0.0259 \\
Blue & 33.73 & \\
Plant tag style/color & & -0.1573 \\
"Slim," black-and- & & 0.0338 \\
gray tag & & 0.0136 \\
"Slim," color photo tag & & 0.1009 \\
Large, color tag & & \\
Keystone-shaped tag & 34.33 & 0.4751 \\
Retail price (US\$) & & -0.0759 \\
1.98 & & -0.3992 \\
2.49 & & \\
3.29 & & \\
\hline
\end{tabular}

${ }^{\mathrm{z}} \mathrm{A}$ higher value indicates a greater importance.

${ }^{\mathrm{y}} \mathrm{A}$ more positive value is more desirable.

Pearson's $R=0.861 ; P=0.0001$.

plant tag style/color $(33.73 \%)$, and retail price $(34.33 \%$, Table 3$)$. Averaged importance is calculated by dividing the range of utility values for an attribute by the sum of these ranges across all attributes, then multiplying by 100 (version 11.0; SPSS). The three factors were considered to have equal importance to participants.

When levels within each factor were examined, differences were apparent. Within the container color factor, only the white container (0.1149) and the blue container (0.0259) received positive utility values, indicating that consumers preferred these container colors to the black options. The keystone shaped tag (0.1099); large, color tag (0.0136); and "slim," color photo tag $(0.0338)$ all received positive ratings for the plant tag style/color factor. The $\$ 1.98$ retail price $(0.4751)$ was the only retail price to receive a positive utility rating; hence, it was the only retail price favored by participants.

Correlation between brand name plant characteristics. Spearman's rho was used to establish correlations between the importance of brand characteristics rated by participants. The closer the correlation coefficient $(r)$ is to \pm 1.000 , the stronger the correlation. Sign indicates the direction of the relationship; for example, negative $r$ would be oppositely correlated, and if $r=1.000$, the attributes were identical (Cronk, 1999).

The test compared the existing PGS attributes (locally grown, independent testing program, ideal for local conditions, and quality assurance) with other national brands attributes to identify relationships and components that consumers may find desirable in the PGS program (Table 4). The top five attributes related to the attribute locally grown were independent testing program $(r=0.418)$, quality assurance $(r=0.413)$, ideal for local conditions $(r=0.396)$, plant guarantee $(r=0.331)$, and publications with gardening tips $(r=0.265$; Table 4$)$. The top five attributes related to the ideal for local conditions attribute were quality assurance $(r=0.609)$, plant guarantee $(r=0.476)$, POP material $(r=0.404)$, locally grown $(r=$ 0.396 ), and publications with gardening tips $(r=0.352)$. The third attribute, quality assurance, was related to ideal for local conditions $(r=0.609)$, plant guarantee $(r=$ $0.593)$, locally grown $(r=0.413)$, publications with gardening tips $(r=0.380)$, and independent testing program $(r=0.355)$. The final attribute, independent testing program, showed a correlation between national spokesperson $(r=0.523)$, locally grown $(r=0.418)$, quality assurance $(r=0.355)$, plant guarantee $(r=0.320)$, and gardening newsletter $(r=0.318)$.

\section{Discussion}

Study 1: Identifying potential Pennsylvania Gardener Selects purchasers. "Avid Gardeners", the most likely target audience for the PSG program, expressed the greatest interest in the PGS concept and had purchased Pennsylvania products in the past. This past purchasing behavior might encourage them to purchase PGS plant material, another Pennsylvania product. These consumers were very active gardeners who felt confident in their ability to make decisions regarding the landscape plant material they purchased. Their shopping habits also demonstrated their interest in gardening and their continual need for plant material and gardening supplies as they shop most frequently for these items during the months of April to August.

Because the PGS program is still in the introductory phase, it is necessary to promote the program's attributes and benefits to the target audience. Successful promotional efforts are achieved through the understanding of the target audience's usage patterns, demographic characteristics, and general goals (Iacobucci, 2001). "Avid Gardeners" indicated that the primary reason they garden was to keep the outside of their home looking beautiful. A promotional campaign for PGS could emphasize factors such as flowering display, uniformity of plant form, vigor, and the other criteria used to evaluate PGS plants (Sellmer et al., 2003), and provide reassurance that PGS plants are quality products and can be used to achieve the results many desire in their own garden or landscape. Display materials for PGS and similar state plant promotional programs could include sample landscape images using the selected plant material in the design. Thus, consumers can visualize how plant material, including PGS, will allow "Avid Gardeners" to create a beautiful exterior to their home (Henne, 2002a).

"Avid Gardeners" are also a desirable consumer segment as $74 \%$ of them are sought after for gardening advice and are recognized by the community as a local source of gardening information. "Novice Gardeners" were most likely to shop at their store of choice because friends recommended the location; hence, it may be possible that these less experienced gardeners rely on "Avid Gardeners" for this and other gardening-related 
Table 4. Correlations between the importance of brand name plant characteristics as rated by intercept survey participants at the 2004 Philadelphia Flower Show on 8 to 10 Mar. 2004.

\begin{tabular}{|c|c|c|c|c|c|}
\hline \multirow[b]{2}{*}{ Attributes } & \multirow[b]{2}{*}{ No. of participants } & \multicolumn{4}{|c|}{ Correlation coefficient, $r$} \\
\hline & & $\begin{array}{l}\text { Locally grown } \\
\quad(\mathrm{n}=184)^{\mathrm{z}}\end{array}$ & $\begin{array}{c}\text { Ideal for } \\
\text { local conditions } \\
(\mathrm{n}=182)^{\mathrm{z}}\end{array}$ & $\begin{array}{l}\text { Quality assurance } \\
\qquad(\mathrm{n}=187)^{\mathrm{z}}\end{array}$ & $\begin{array}{c}\text { Independent } \\
\text { testing program } \\
(\mathrm{n}=184)^{\mathrm{z}}\end{array}$ \\
\hline Website with gardening information & 184 & -0.100 & 0.140 & 0.002 & 0.002 \\
\hline Gardening seminars & 188 & $0.181 *$ & 0.100 & 0.085 & $0.292 *$ \\
\hline Suggested flower color combinations & 181 & $0.203^{*}$ & $0.197 *$ & $0.301 *$ & $0.249^{*}$ \\
\hline Gardening newsletter & 184 & $0.203 *$ & $0.276^{*}$ & $0.268^{*}$ & $0.318^{*}$ \\
\hline National spokesperson & 179 & $0.263 *$ & -0.027 & 0.140 & $0.523 *$ \\
\hline Locally grown & 184 & 1.000 & $0.396^{*}$ & $0.413 *$ & $0.418^{*}$ \\
\hline Ideal for local conditions & 182 & $0.396^{*}$ & 1.000 & $0.609 *$ & $0.214^{*}$ \\
\hline Quality assurance & 187 & $0.413 *$ & $0.609 *$ & 1.000 & $0.355^{*}$ \\
\hline Independent testing program & 184 & $0.418 *$ & $0.214 *$ & $0.355^{*}$ & 1.000 \\
\hline Plant guarantee & 189 & $0.331 *$ & $0.476^{*}$ & $0.593 *$ & $0.320 *$ \\
\hline
\end{tabular}

${ }^{2}$ Attributes: Locally grown, ideal for local conditions, quality assurance, and independent testing program, are the premise of the Pennsylvania Gardener Selects program.

*Significant at $\alpha=0.05$.

POP, point of purchase.

information. If "Avid Gardeners" are satisfied and pleased with the PGS program, they may recommend the program to others, primarily those who rely on their expertise and knowledge. This form of promotion, word of mouth, is a very powerful tool because it is based on someone's personal experience (Gobe, 2001).

Both "Novice Gardeners" and "Casual Gardeners" appear to be less of a target audience for any initial marketing strategy developed and implemented for the PGS program. Although a majority of "Novice Gardeners" have purchase Pennsylvania products in the past $(83 \%)$, they expressed little interest in the concept of the program. "Casual Gardeners" also expressed very little interest in the PGS concept. Based on this and other differences in attitudes and interest in gardening, two separate marketing strategies may be needed. The first would target the "Avid Gardeners" and build on their experience, needs, and wants. The second would target "Novice Gardeners" and "Casual Gardeners" and would focus on program attributes and benefits that would appeal to them-for example, that plants selected for the program were independently tested in 44 trial locations throughout the state and are ideal for all the environmental conditions experienced in Pennsylvania. Pennsylvania Gardener Selects plants may appeal to "Novice Gardeners" and "Casual Gardeners", based on the selection process used to identify suitable plants, because their confidence to make decisions about the landscape plant material they purchased was neutral at best.

Study 2: Preference for Pennsylvania Gardener Selects point-of-purchase material, retail price, and brand attributes. None of the three factors (container color, plant tag style/ color, or retail price) were considered more important than any other by participants. Participants chose the white container as the color option that appealed to them the most, followed by blue and then black containers. Consumers may have preferred the white container because it may emphasize the plant and does not clash with other colors. Growers and retailers should take notice, because the standard black container, which was the least valued, is commonly used at most garden centers (Doeckel, 2002).

Consumers are also looking for a container tag style different from generic labels found in most garden centers (Doeckel, 2002). In the current study, participants chose one of the most ornate plant tag options available: the tag in the shape of a keystone. Participants reported that they associate the keystone shape with the state of Pennsylvania and, because PGS was a Pennsylvania product, they felt it would be the most appropriate symbol for plant tags and other POP material. Because uniquely shaped tags are expensive to produce and their investment may not justify the results (Naab, 2003), an alternative (participants' second choice) is the "slim," color photo tag. An advantage is that this tag is a standard size used commonly in the green industry and, by adding a color image of the plant in peak flower, it contains a characteristic similar to that of the larger, more expensive keystone-shaped tag.

Consumer acceptability of a product's price is the degree to which the product is important to the buyer (Ofir, 2004). Participants selected the lowest price $(\$ 1.98)$ as their primary choice, which may be a basic reaction to price-specifically, that "the lowest price is better" (Ofir, 2004).

When evaluating the images and rating the three factors, participants received no information that explained the benefits that plants labeled PGS would provide the purchaser. As a result, the product presented in the images may have held no increased importance to consumers compared with another labeled plant product. Benefits that are of greatest interest and importance to "Avid Gardeners" should be stated on labels, POP signs, and related materials. Explanations of how plants can meet their needs and wants, such as: diverse plant selection/ unusual species, being a quality product, and enhancing the beauty of the outside of the home, may be more appealing to the "Avid Gardeners" and could command a higher retail price.

The attributes quality assurance, plant guarantee, locally grown, and publication with gardening tips consistently appeared among the attributes that closely correlated to each of the four existing attributes. Current PGS attributes-locally grown and quality assurance - also had strong correlations with the other two PGS attributes: independent testing and ideal for local conditions. These results indicate that all the current PGS attributes were strongly linked in participants' minds; therefore, they should continue to be the main focus of promotion.

In addition, there was a strong correlation between PGS attributes and the attributes of plant guarantee and publications with gardening tips. Incorporating these important attributes into the PGS program, possibly with cooperative extension resources such as gardening fact sheets and other publications, could be a way to build the program further.

\section{Conclusion}

Based on the data, the best marketing strategy would be to cater to the needs and wants of the "Avid Gardener", because members of this segment currently purchase Pennsylvania products, have an interest in the premise of the PGS program, and purchase plant material and gardening supplies throughout the gardening season. Spending resources - both time and money- to connect with this segment as the first step in promoting the program would be a wise approach.

Survey participants were asked to consider realistic brand attributes and viewed representative images of PGS plant material as they would appear in a retail environment. Consumers unfamiliar with this brand of plant material will first use visual characteristics 
when determining whether to investigate the brand's perceived value and to determine whether further investigation of the brand's usefulness is warranted. Thus, branded plant programs should focus on using uniquely shaped plant tags or standard shaped tags with vibrant colors to attract consumer attention, and they should avoid the use of generic black and green containers. To further develop a program that appeals to consumers, strategies should be integrated, such as: describing solutions that plants offer the purchaser and incorporating additional attributes (publications with gardening tips and a plant guarantee) to already existing program features. Such effort will help strengthen the brand's position and value.

\section{Literature Cited}

Bruner, G.C., II and P.J. Hensel. 1996. Marketing scales handbook. Amer. Mktg. Assoc., Chicago, Ill.

Crawford, F. and R. Mathews. 2001. The myth of excellence. Crown Business, New York.

Creel, K. 2004. Branding part II: What do the numbers say? Lawn Garden Retailer 3:52-55.

Cronk, B. 1999. How to use SPSS: A step-by-step guide to analysis and interpretation. Pyrczak Publishing, Los Angeles, Calif.
Doeckel, B. 2002. Improving the retail experience for shoppers. Greenhouse Grower 20:140-141.

Eaton Farms. 2003. Pennsylvania Pride Nursery Farms. 30 June 2004. < www.pennsylvaniapride. com/\#guarantee>.

Gibson, J. and L. Greer. 2003. Signs of the times. Greenhouse Grower 21:56-60.

Gobe, M. 2001. Emotional branding. Allworth, New York.

Henne, L. 2002a. Branding in action: Proven Winners. Greenhouse Grower 20:78-82.

Henne, L. 2002b. Branding in action: Simply Beautiful. Greenhouse Grower 20:96-112.

Iacobucci, D. (ed.). 2001. Kellogg on marketing. Wiley, New York.

Kelley, K.M., B.K. Behe, J.A. Biernbaum, and K.L. Poff. 2001. Consumer preference of edible-flower color, container size, and price. HortScience 36:801-804.

Kelley, K.M., B.K. Behe, J.A. Biernbaum, and K.L. Poff. 2002. Combinations of colors and species of containerized edible flowers: Effect on consumer preferences. HortScience 37:218-221.

Kelley, K.M. and E.S. Sanchez. 2005. Accessing and understanding consumer awareness of and potential demand for edamame (Glycine max [L.] Merrill). HortScience 40:1347-1353.

Kress, G. 1988. Marketing research. 3rd ed. Prentice-Hall, Englewood Cliffs, N.J.

Mackay, W., S. George, T. Davis, M. Arnold, R.D. Lineberger, J. Parsons, L. Stein, and G. Grant.
2001. Texas Superstar and the coordinated educational and marketing assistance program (CEMAP): How we operate. HortTechnology 11:386-391.

Miller, C. 2003. Spring price survey 2003. Garden Center Merchandising Manage. 9:36-41.

Naab, V. 2003. Packaging: The next frontier. Greenhouse Grower 21:67-69.

Ofir, C. 2004. Reexamining latitude of price acceptability and price thresholds: Predicting basic consumer reaction to price. J. Consum. Res. 30:612-622.

Sellmer, J.C., R.D. Berghage, A.H. Michael, and T. Bilik. 2003. Pennsylvania Gardener Selects Evaluation Program. <www.joe.org/joe/ 2003february/iw4.shtml $>$. Accessed 13 May 2004.

Sellmer, J.C., N. Ostiguy, K. Hoover, and K.M. Kelley. 2004a. Assessing the integrated pest management practice of Pennsylvania nurseries. HortScience 39:297-302.

Sellmer, J.C., N. Ostiguy, K. Hoover, and K.M. Kelley. 2004b. Assessing the integrated pest management practices of Pennsylvania, U.S., landscape companies. J Arboriculture 30:253259.

Talaga, J. and L. Tucci. 2001. Consumer tradeoffs in on-line textbook purchasing. J. Consum. Mark. 18:10-18.

Whery, R. 2004. Developing a plant promotional program: A marketing effort. Pa. State. Univ., Univ. Park, Pa. MS thesis. 